\title{
Parental Catastrophizing Partially Mediates the Association between Parent-Reported Child Pain Behavior and Parental Protective Responses
}

\author{
Shelby L. Langer, ${ }^{1}$ Joan M. Romano, ${ }^{2}$ Lloyd Mancl, ${ }^{3}$ and Rona L. Levy ${ }^{1}$ \\ ${ }^{1}$ School of Social Work, University of Washington, Box 354900, 4101 15th Avenue NE, Seattle, WA 98105, USA \\ ${ }^{2}$ Psychiatry and Behavioral Sciences, School of Medicine, University of Washington, Box 356560, \\ 1959 Pacific Street, Seattle, WA 98195, USA \\ ${ }^{3}$ Oral Health Sciences, School of Dentistry, University of Washington, Box 357475, 1959 NE Pacific Street, Seattle, WA 98195, USA
}

Correspondence should be addressed to Shelby L. Langer; shelbyl1@uw.edu

Received 31 July 2013; Revised 31 October 2013; Accepted 2 November 2013; Published 20 January 2014

Academic Editor: S. Evers

Copyright (C) 2014 Shelby L. Langer et al. This is an open access article distributed under the Creative Commons Attribution License, which permits unrestricted use, distribution, and reproduction in any medium, provided the original work is properly cited.

\begin{abstract}
This study sought to model and test the role of parental catastrophizing in relationship to parent-reported child pain behavior and parental protective (solicitous) responses to child pain in a sample of children with Inflammatory Bowel Disease and their parents ( $n=184$ dyads). Parents completed measures designed to assess cognitions about and responses to their child's abdominal pain. They also rated their child's pain behavior. Mediation analyses were performed using regression-based techniques and bootstrapping. Results supported a model treating parent-reported child pain behavior as the predictor, parental catastrophizing as the mediator, and parental protective responses as the outcome. Parent-reported child pain behavior predicted parental protective responses and this association was mediated by parental catastrophizing about child pain: indirect effect $(\mathrm{SE})=2.08(0.56)$; $95 \%$ $\mathrm{CI}=1.09,3.30$. The proportion of the total effect mediated was $68 \%$. Findings suggest that interventions designed to modify maladaptive parental responses to children's pain behaviors should assess, as well as target, parental catastrophizing cognitions about their child's pain.
\end{abstract}

\section{Introduction}

Catastrophizing cognitions regarding pain have emerged as important predictors of pain-related outcomes [1]. Research spanning both child and adult samples suggests that catastrophizing amplifies pain experience, expressivity, and painrelated dysfunction [2]. For example, catastrophizing among adults has been associated with increased pain intensity, severity and interference, increased pain behavior, decreased pain tolerance, increased depression and distress, and increased disability [3-10]. Similarly, catastrophizing among children has been associated with increased pain intensity, severity and pain-related attentional avoidance, increased pain anxiety and pain behavior, increased depression and distress, increased functional disability, and decreased healthrelated quality of life [11-20].
From a theoretical standpoint, catastrophizing has been conceptualized as an appraisal process, a cognitive coping strategy, and a means of coping via elicitation of communal support [2]. In a critical review of the literature on catastrophizing, Quartana and colleagues [2] note that pain catastrophizing in particular is characterized by the tendency to magnify the threat value of a pain stimulus, to feel helpless in the face of pain, and by difficulty inhibiting painrelated thoughts. The assessment of catastrophizing has been conducted primarily through self-report questionnaires such as the Coping Strategies Questionnaire [21] and the Pain Catastrophizing Scale (PCS; [22]). Factors within the larger category of catastrophizing have been derived from the PCS, indicating dimensions of rumination, magnification, and helplessness [22]. More recently, attention to catastrophizing among significant others such as spouses/partners or parents 
of those with pain has led to the development of instruments such as the PCS-Spouse [23] and PCS-Parent forms [24], designed to assess catastrophizing cognitions in response to a loved one's pain.

With these measures, researchers have begun to examine effects that the catastrophizing cognitions of significant others may have on patient outcomes. Relatively recent studies have demonstrated that parents' catastrophic cognitions about their child's pain are associated with adverse outcomes in the child such as increased pain intensity, increased (parent-perceived) pain behavior, increased pain catastrophizing, increased depressive symptomatology, increased disability, and decreased quality of life $[15,16,19,25]$. Parents' catastrophizing about their child's pain has also been associated with the parents' emotional and behavioral responses to their child's pain. For example, Hechler and colleagues [25] found that both mothers' and fathers' catastrophizing about their child's chronic pain was associated with self-reported solicitous responding to the child's pain (responding in ways that reinforce symptomatology and illness behavior). In a laboratory study in which children were asked to undergo a cold-pressor procedure, parents' catastrophizing about their child's pain was positively associated with their self-reported distress and tendency to want to stop the procedure [26]. In a third study employing a vignette methodology, mothers' catastrophizing about their child's pain was associated with greater endorsement of items reflecting the importance of controlling their child's pain in a hypothetical pain scenario relative to the importance of having their child engage in everyday activities despite the pain [27]. It should be noted, however, that this association only held for hypothetical scenarios involving acute versus chronic pain [27]. Finally, in a naturalistic study of children with leukemia undergoing lumbar puncture and/or bone aspiration procedures, heightened catastrophic thinking about the child's procedural pain was associated with greater distress among parents during the procedure. Increased distress among high catastrophizing parents, moreover, predicted greater pain-attending verbal and nonverbal behavior while interacting with their child after the procedure [28].

While parental catastrophizing appears to be an important factor potentially influencing emotional and behavioral responses to pain in children and their parents, the exact nature of its role remains to be clarified. In a cognitivebehavioral model, cognitive appraisals have been viewed as a mediator between events (or perceived events) and emotional and behavioral responses. Thus, appraisals of threat are seen as activating emotional and behavioral responses to perceived stressors [29]. In this framework, child pain behaviors may serve as triggers that increase the likelihood of catastrophizing cognitions on the part of parents, which in turn may prompt responses to protect the child or mitigate threat. This model is illustrated in Figure 1. We have already outlined evidence for Paths a and b. With respect to Path $\mathrm{c}$, the association between child pain behavior and parental protective responses, results from a heat pain induction experiment indicated that parents engaged in more painattending talk with their child if the child talked more about his/her pain [30]. This effect was moderated, moreover, by

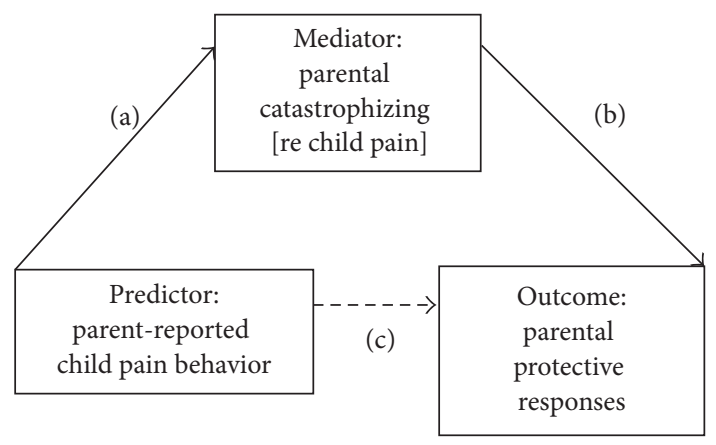

FIGURE 1: Conceptual model treating parental catastrophizing as a mediator.

perceived threat. High catastrophizing parents who were led to believe that the heat induction was threatening engaged in more pain-attending talk (e.g., asking their child, "Does it still hurt?") than did high catastrophizing parents who were led to believe that the heat induction was neutral (nonthreatening). In contrast, pain-attending talk did not differ as a function of perceived threat among low catastrophizing parents [30].

This model may be particularly relevant in a population such as that of children with Inflammatory Bowel Disease (IBD) and their parents. IBD is the umbrella term for two serious and chronic medical disorders, Crohn's Disease and ulcerative colitis, and is seen with increasing frequency among children [31]. Both conditions are diagnosed after positive medical tests have determined chronic inflammation in the gastrointestinal tract. Clinical features can include malaise, diarrhea, blood and/or mucus in the stool, abdominal pain, anemia, weight loss, fever, abscess, and fistula; malnutrition is common [32, 33]. Extradigestive manifestations may also occur [34]. IBD has been associated with significant personal and societal costs, including depression, anxiety, social deficits, self-management difficulties, poor school functioning, decreased health-related quality of life, and increased health care expenditures [35-40]. The presentation of IBD is frequently variable, marked by symptom flares as well as extended quiescent periods in which few symptoms occur or in which pain behaviors may be infrequent or absent. Increased symptoms, which may or may not indicate underlying increased disease activity, can be accompanied by significant discomfort and pain behavior. Thus, parent perception of pain behaviors may have the effect of triggering or activating threat appraisals and catastrophic cognitions on the part of parents, which could then lead to increased protective responses. In the case of a disease that often presents with a pattern of episodic increases in symptoms and potentially more severe disease activity, it is plausible that parental catastrophizing may be activated by the perception of increased child pain behavior to a greater extent than in chronic pain conditions where symptoms are more constant or where there is no evidence of underlying disease.

An alternate conceptual model is presented in Figure 2. In this model, parental catastrophizing might be viewed as a dispositional, predictive factor leading to parental protective responses, mediated by the perception of pain behavior. 


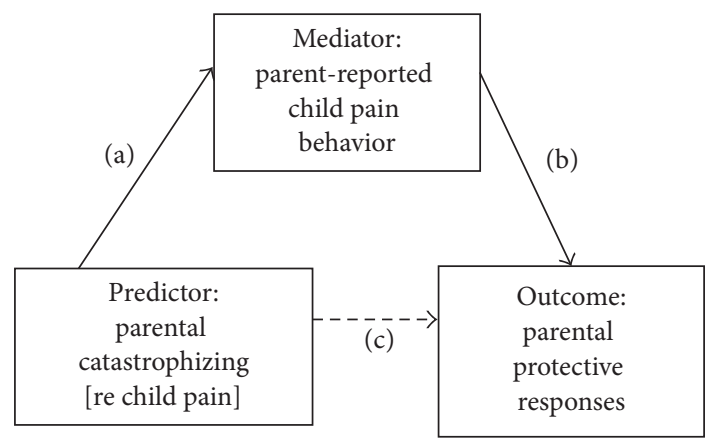

FIGURE 2: Conceptual model treating parental catastrophizing as a predictor.

Catastrophizing in this context might increase the likelihood that parents perceive pain behaviors on the part of the child, perhaps through heightened sensitivity or vigilance regarding the threat that they represent. In an empirical demonstration of this notion, undergraduates were shown videos of other research participants undergoing a cold-pressor procedure [41]. The undergraduates (termed viewers) were asked to make judgments regarding the level of pain intensity experienced by the participants in the videos. Viewers higher in catastrophizing judged the participants as experiencing more intense pain than did viewers low in catastrophizing. Posthoc analyses indicated that high catastrophizers were more likely to rely on pain behavior in inferring pain experience; such inferences, however, were not necessarily more accurate. Further evidence comes from a study of school children asked to undergo a pain pressure test [42]. Each child's primary caregiver (mostly mothers) observed this process via a television screen in a separate room. Parents' catastrophizing about their child's pain was associated with higher ratings of their child's pain experience. This effect was independent of their child's observer-coded facial pain expressions, lending support for a "top-down" or observer-driven view of pain perception. Catastrophizing among parents may increase the likelihood of their perceiving child symptoms as a cause for concern or perceiving child behaviors as indicative of pain experience. This may come to influence the responses of parents of children with chronic pain over time.

Very little is known about these processes in pediatric IBD. To our knowledge, only one study has examined parental catastrophic cognitions and protective responses to child gastrointestinal symptoms in the context of IBD. This was a pilot intervention designed to improve coping among female adolescents with IBD and their parents [43]. Treatment consisted of a 1-day workshop followed by several weeks of web-based skill review and practice; sessions targeted, in part, catastrophic cognitions and parental responses, training parents to set appropriate limits and expectations. Families also received communication skills training. Adolescents in the intervention group evidenced prepost treatment reductions in somatic symptoms and improvements in pain coping, and parents reported reductions in catastrophic cognitions and improved (less protective) behavioral responses to their daughter's symptoms. This same group also published a manuscript describing factors associated with attrition from the intervention. Baseline levels of parental catastrophizing were higher among families who dropped out versus completed [44]. While these findings offer important implications for intervention, we still know very little about baseline levels of cognitive and interpersonal processes in this population, not to mention associations among these factors. This study was also small in size (13 assigned to the intervention and 11 assigned to wait-list control) and excluded prepubertal children and male adolescents [43].

In summary, there is only a very small body of literature examining parental catastrophizing and protectiveness and how they relate to child symptoms and functioning in pediatric IBD, a pain-related condition with significant psychosocial costs. In the current study, we tested two models representing parental catastrophizing as either a mediating or predictive factor in relationship to protectiveness, to determine which would be more consistent with data from a sample of children with IBD and their parents.

\section{Materials and Methods}

2.1. Participants. One-hundred and eighty-four parent-child dyads served as participants, a subsample of 210 dyads enrolled in a randomized controlled trial (RCT) of a cognitive-behavioral intervention designed to help families manage pediatric IBD. The RCT, still ongoing, is prospective and longitudinal; the present data were collected at baseline, prior to randomization. Of the 210 dyads enrolled, 26 were excluded from our analysis subsample. Twenty families did not complete baseline assessment. One child completed baseline assessment but his/her parent did not. Five additional dyads were randomly excluded to avoid nonindependence among siblings (these five families each had two children with IBD enrolled in the study).

Families were recruited from the gastroenterology departments of Seattle Children's Hospital in Seattle, WA, and Mary Bridge Children's Hospital in Tacoma, WA. All procedures were approved by the Institutional Review Boards of both institutions. Children and parents were included if the child was age 8-17, had a diagnosis of IBD for at least 3 months, was medically approved to engage in normal daily activities, and if the child and parent had cohabited for at least the past 3 months. Exclusion criteria included child chronic disease other than IBD, major surgery in the past year unrelated to IBD, and developmental disability requiring fulltime special education or impairing the ability to respond. Participants also needed to be able to speak and comprehend English.

2.2. Parent-Reported Measures. Parents completed measures online or, if preferred, via pencil and paper by mail. Questionnaires are described in turn below.

The Pain Catastrophizing Scale-Parent [24] assessed parents' catastrophizing about their child's abdominal pain and other gastrointestinal symptoms. Thirteen items such as "I worry all the time whether my child's pain will end" are rated on a $0-4$ scale; summary scores can range from $0-52$. The developers reported strong internal consistency $(\alpha=0.93)$ 
and validity as demonstrated by associations with parent distress and child disability. In our sample, Cronbach's coefficient alpha was 0.92 . We used total scores given strong intercorrelations among the subscales and with the total $(r$ values ranging from $0.68-0.91, P<.001$ ).

The protect subscale of the Adult Responses to Children's Symptoms [45] was used to assess parents' solicitous responses to their children's gastrointestinal symptoms. Exemplar items include "When your child has a stomachache or abdominal pain, how often do you... let him/her stay home from school," "...bring him/her special treats or little gifts," and "...get him/her something to eat or drink?" Internal consistency values in the literature range from 0.82 to 0.86 [45-47]. The value based on the present sample was 0.87 . Thirteen items are rated on a $0-4$ (never to always) scale; summary scores can range from 0-52 [46]. While the measure contains three factor-analytically derived subscales, only the protect subscale has undergone validity testing, associated with a diary version of the subscale, healthcare visits for gastrointestinal symptoms [47], and child pain and functional disability [48].

The Pain Behavior Check List (PBCL; [49]) was used to assess parents' reports of observable expressions of their child's pain. The PBCL was developed for use with adult chronic pain patients and has demonstrated satisfactory reliability and validity [49]; psychometric properties were also established using a nonclinical college sample [50]. We adapted the PBCL for use by parents in assessing child pain behaviors. Most pediatric pain behavior measures were developed in the context of assessing behavior in acute procedural pain situations or acute injury/illness contexts, or to be completed by trained observers [51] and thus were not applicable in the assessment of chronic pain behaviors by parents. In adapting the PBCL for this study, certain items were modified for use with our pediatric/adolescent sample. For example, "take pain medication" was changed to "take medicine," "walk with a limp or distorted gait" was changed to "walk with a limp or in a different way than usual," and "use a cane or some other prosthesis" was omitted. We also added "lie down." All items were rated for frequency on a $0-4$ (never to always) scale. The developer reported a Cronbach's coefficient alpha of 0.85 for the total scale; the value based on the present dataset was 0.89 . We also used our sample to examine validity. Total PBCL scores were positively correlated with parentreported child functional disability $(r=.32, P<.001)$ and child-reported functional disability $(r=.35, P<.001)$ using the Functional Disability Inventory $[52,53]$; child-reported gastrointestinal symptom severity $(r=.17, P=.025)$ using the Children's Somatization Inventory [54]; and childreported massaging/guarding the painful area $(r=.18, P=$ .014), a subscale of the Pain Response Inventory [55]. Conversely, total PBCL scores were inversely correlated with parent-reported child quality of life $(r=-.42, P<.001)$ and child-reported quality of life $(r=-.34, P<.001)$ using the Pediatric Quality of Life Inventory [56].

2.3. Child-Reported Measures. Children completed questionnaires via phone, administered by a nurse researcher. To
TABLE 1: Sample characteristics ( $n=184$ dyads).

\begin{tabular}{lcc}
\hline Characteristic & Parent & Child \\
\hline Age, M (SD) & $44.37(6.85)$ & $13.72(2.72)$ \\
Age, range & $27-67$ & $8-18$ \\
Gender, $n$ (\%) female & $166(90.2)$ & $87(47.3)$ \\
Ethnicity, $n$ (\%) Hispanic & $3(1.6)$ & $8(4.3)$ \\
Race, $n(\%)$ Caucasian & $171(92.9)$ & $162(88.0)$ \\
Education, $n$ (\%) 4-year college & $90(48.9)$ & - \\
degree or higher & & - \\
Employment status, $n$ (\%) employed & $81(44.0)$ & - \\
full-time & $145(78.8)$ & - \\
Marital status, $n$ (\%) married & & $126(68.5)$ \\
Disease, $n$ (\%) & - & $58(31.5)$ \\
$\quad$ Crohn's Disease & - & $2.30(2.41)$ \\
$\quad$ Ulcerative colitis & - & \\
Time since diagnosis in years, & M (SD)
\end{tabular}

facilitate comprehension, answer choices were mailed to children in advance of the phone session. We focus here on the Faces Pain Scale-Revised [57], a validated single-item measure of current pain intensity. Children are shown a row of 6 line-drawn faces. The left-most face depicts no pain, with the faces depicting more and more pain as they move from left to right. Children are instructed to choose the face that shows "how much they hurt right now." Options are scored as 0 (no pain) to 10 (very much pain). In our sample, this item correlated positively with children's ratings of the extent to which they were bothered by pain in their stomach or abdomen in the past two weeks $(r=0.38, P<.001)$, an item contained in the Children's Somatization Inventory [54].

2.4. Analyses. Descriptive statistics and correlation analysis were used to describe the sample with respect to demographics and key study variables. Mediation analysis was performed using Hayes' PROCESS macro, a regression-based path analytic technique. Bootstrap methods were used to test for an indirect effect and to compute bias-corrected confidence intervals for this effect [58]. Child age, gender, and current pain were included as covariates in all mediation models. Analyses were conducted using IBM Statistical Package for the Social Sciences 20.0.

\section{Results}

3.1. Sample Characteristics. Table 1 presents demographic characteristics of parents and children. Parents were, on average, 44 years old. The majority were mothers, non-Hispanic, and Caucasian. Almost one-half had earned a four-year college degree, $79 \%$ were married, and $44 \%$ were employed fulltime. Their children were, on average, 13.7 years old. Child gender was fairly evenly distributed (47\% female and 53\% male). Approximately two-thirds had a diagnosis of Crohn's Disease and one-third had a diagnosis of ulcerative colitis. 
TABLE 2: Correlations among study variables and descriptive statistics $(n=184)$.

\begin{tabular}{|c|c|c|c|c|c|c|c|c|}
\hline & 1 & 2 & 3 & 4 & 5 & 6 & $\mathrm{M}(\mathrm{SD})$ & Scale \\
\hline (1) Child age & 1.00 & .02 & .02 & -.11 & -.01 & -.08 & $13.72(2.72)$ & NA \\
\hline (2) Child gender (M 1, F 2) & & 1.00 & -.02 & $.18^{*}$ & .00 & -.01 & NA & NA \\
\hline (3) Child current pain & & & 1.00 & .04 & .02 & .04 & $0.51(1.46)$ & $0-10$ \\
\hline (4) Parent-reported child pain behavior & & & & 1.00 & $.42^{* *}$ & $.24^{* *}$ & $1.53(0.66)$ & $0-4$ \\
\hline (5) Parental catastrophizing & & & & & 1.00 & $.40^{* *}$ & $20.55(10.77)$ & $0-52$ \\
\hline (6) Parental protective responses & & & & & & 1.00 & $22.41(8.65)$ & $0-52$ \\
\hline
\end{tabular}

Note: ${ }^{*} P<.05$ and ${ }^{* *} P<.01$.

TABLE 3: Results of mediation analyses treating parent-reported child pain behavior (PRCPB) as the predictor, parental catastrophizing (CAT) as the mediator, and protective responses as the outcome $(n=184)$.

\begin{tabular}{|c|c|c|c|c|}
\hline Path & Effect & Estimate (SE) & $P$ & $95 \% \mathrm{CI}$ \\
\hline c & Effect of PRCPB on protect & $3.04(0.97)$ & 0.002 & - \\
\hline $\mathrm{a}$ & Effect of PRCPB on parent CAT & $7.07(1.12)$ & $<0.001$ & - \\
\hline $\mathrm{b}$ & Effect of parent CAT on protect & $0.32(0.05)$ & $<0.001$ & - \\
\hline$a \times b$ & Indirect effect & $2.08(0.56)$ & - & $1.09,3.30$ \\
\hline$c^{\prime}$ & Direct effect & $0.96(1.01)$ & 0.342 & \\
\hline
\end{tabular}

Note: confidence intervals excluding zero indicate statistical significance. The ratio of the indirect effect $(\mathrm{a} \times \mathrm{b})$ to the total effect $(\mathrm{c})$ or the proportion of the total effect mediated was 0.68 .

Table 2 displays descriptive statistics for study variables in addition to a correlation matrix. With respect to bivariate associations, gender was associated with child pain behavior such that girls were judged by their parents to exhibit more pain behavior than were boys. Child age and pain intensity were unrelated to key study variables. Parent-reported child pain behavior, parent catastrophizing, and parent protective responses were all significantly positively associated with each other.

3.2. Mediation Analyses. Table 3 displays results of the mediation analyses treating parent-reported child pain behavior as the predictor, parental catastrophizing as the mediator, and parental protective responses as the outcome (Figure 1). Parent-reported child pain behavior was significantly related to both parental protective responses (Path c, estimate $=3.04$, $P<.01$ ) and parental catastrophizing (Path a, estimate $=7.07$, $P<.001)$. Parental catastrophizing was significantly related to parental protective responses (Path $b$, estimate $=0.32$, $P<.001)$. The mediation hypothesis was supported by a significant indirect effect as indicated by the confidence interval excluding zero (Path $\mathrm{a} \times \mathrm{b}$, estimate $=2.08$; 95\% CI with $10,000$ resamples $=1.09,3.30)$. When both the predictor and mediator were entered into the model, Path $b$ remained significant, whereas the effect of parent-reported child pain behavior on protective responses was no longer significant (Path $c^{\prime}$, estimate $=0.96, P>.05$ ). The ratio of the indirect effect to the total effect or the proportion of the total effect mediated was $68 \%$, indicating support for partial mediation.

Table 4 displays results of mediation analyses treating parental catastrophizing as the predictor, parent-reported child pain behavior as the mediator, and protective responses as the outcome. Parental catastrophizing was significantly related to both parental protective responses (Path c, estimate $=0.32, P<.001)$ and parent-reported child pain behavior
(Path a, estimate $=0.03, P<.001)$. Parent-reported child pain behavior was significantly related to parental protective responses (Path $\mathrm{b}$, estimate $=3.04, P<.01$ ). However, the hypothesis of parent-reported child pain behavior as a mediator was not supported as indicated by a nonsignificant indirect effect $($ Path $\mathrm{a} \times \mathrm{b}$, estimate $=0.02 ; 95 \% \mathrm{CI}$ with 10,000 resamples $=-0.02,0.07)$. When both the predictor and mediator were entered into the model, the effect of parental catastrophizing on protective responses remained significant (Path $c^{\prime}$, estimate $\left.=0.29, P<.001\right)$.

\section{Discussion}

This study sought to test two conceptualizations of the role of parental catastrophizing in relation to parent-reported child pain behavior and parental responses to children's stomachaches and other gastrointestinal symptoms in children with IBD. We found that parent-reported child pain behavior predicted protective responses and this association was partially mediated by parental catastrophizing. An alternative mediation model treating parental catastrophizing as the predictor, parent-reported child pain behavior as the mediator, and protective responses as the outcome was not supported. At least for the present IBD sample, then, the data supported a model in which catastrophic cognitions may be activated in response to perceived child pain behaviors, and such cognitions, in turn, are associated with protective responses.

Findings highlight the importance of parents' cognitions in influencing responses to their children's pain behaviors and suggest directions for the design of psychosocial interventions targeted toward parents as a possible means of influencing child pain behavior and functioning. Our research group has previously demonstrated efficacy of a cognitivebehavioral intervention for children with functional (i.e., 
TABLE 4: Results of mediation analyses treating parental catastrophizing (CAT) as the predictor, parent-reported child pain behavior (PRCPB) as the mediator, and protective responses as the outcome $(n=184)$.

\begin{tabular}{|c|c|c|c|c|}
\hline Path & Effect & Estimate (SE) & $P$ & $95 \% \mathrm{CI}$ \\
\hline c & Effect of CAT on protect & $0.32(0.05)$ & $<0.001$ & - \\
\hline a & Effect of CAT on PRCPB & $0.03(0.004)$ & $<0.001$ & - \\
\hline $\mathrm{b}$ & Effect of PRCPB on protect & $3.04(0.97)$ & 0.002 & - \\
\hline$a \times b$ & Indirect effect & $0.02(0.03)$ & - & $-0.03,0.07$ \\
\hline$c^{\prime}$ & Direct effect & $0.29(0.06)$ & $<0.001$ & - \\
\hline
\end{tabular}

Note: confidence intervals excluding zero indicate statistical significance. The proportion of the indirect effect $(\mathrm{a} \times \mathrm{b})$ to the total effect $(\mathrm{c})$ or the proportion of the total effect mediated was $0.08(0.0245 / 0.3184)$.

recurrent, unexplained) abdominal pain and their parents $[59,60]$. An important goal of the cognitive component was reduction of pain-related catastrophic cognitions among both children and parents. A social learning component encouraged parents to respond to their children's symptoms in ways that encouraged activity and reinforced wellness versus illness behavior, important given research demonstrating links between parental solicitous responses to child gastrointestinal symptoms and child symptom severity and disability $[13,61,62]$. The present findings support this approach.

The present findings also offer specific implications for research-based interventions in the context of pediatric IBD. One of these is that reduction of parental catastrophizing in response to child pain behaviors in this population should be considered an important treatment goal. Parents could be trained in fairly standard cognitive methods, such as "look at the evidence for..." or "try practicing alternative thoughts" to manage catastrophizing. It might also be helpful to have parents examine cognitions that arise in response to specific situational cues and to role-play responses to these cognitions, such as reviewing guidelines for when it is appropriate to call the child's physician versus engage in self-management. In addition to targeting and reframing catastrophic cognitions directly, interventions could target the impact or consequences of catastrophizing. For parents, this might include managing their own stress or distress in ways that enable them to respond more adaptively to their child [63].

Given the importance of parental cognitions and behaviors, another implication of the present findings is that interventions targeted only to parents, as opposed to parentchild dyads, might be effective in improving outcomes in children with pain and other symptoms where environmental factors can play a key role in pain expression and ability to cope with symptoms. Such an intervention might focus on decreasing catastrophizing in parents as well as teaching parents strategies to manage their own distress or to minimize maladaptive responses to child distress and pain behaviors. This approach might provide an avenue for simpler, costeffective, and more efficient methods of treatment delivery.

As stated previously, this study utilized baseline data from a cognitive-behavioral intervention study for children with IBD and their families. As this trial is still underway and we do not yet know whether the intervention produced improved outcomes such as reduced child gastrointestinal symptom severity, we cannot yet test mechanisms or mediators of outcome such as whether changes in parent or child cognitions, or parent responses mediate treatment effects if found. Because IBD has a well-established etiology with significant morbidity, parental appraisals regarding child pain and prognosis occur in a different context than appraisals of parents of children with abdominal pain with no known physiological etiology (functional abdominal pain). However, it is also quite possible that interpersonal factors affecting a child's ability to cope with illnesses with and without well-established etiologies may be similar.

Several limitations of the present study should be addressed. First, we relied on parent-report measures of child pain behavior and parental response. Future research will benefit greatly from the inclusion of both child-report indicators of parent behavior and objective measures of both child and parent behaviors, assessed in a naturalistic or in vivo pain situation. Relatedly, our measure of pain behavior (the PBCL) was developed using an adult sample. While internal consistency for our sample was good and the scale correlated positively with measures of child disability and pain response, formal psychometric evaluation of a parent/child adaptation of this measure has not been conducted. Use of a childspecific, and perhaps even abdominal pain-specific, measure of pain behavior is advised. Second, our sample was comprised largely of mothers and results may not generalize to fathers. Mothers report higher levels of catastrophizing than fathers [25]. Replication in a more evenly distributed sample is advised. Third, given the cross-sectional and associational nature of our data, we cannot infer directionality, sequence, or causality. Parent-reported child pain behavior and parental protective responses were measured concurrently and were positively correlated. Thus, it is not surprising that when we tested a reverse mediation model treating protective responses as the predictor, parental catastrophizing as the mediator, and parent-reported child pain behavior as the outcome, our data supported this model, lending further support for a linkage between these two outcomes through parental catastrophizing when factors are measured contemporaneously. Future research is needed, however, to clearly elucidate directionality of Path c. Investigations utilizing a repeated measures design are warranted to explicate timing and sequence, as done in observational studies of patients and spouses in the adult chronic pain arena [64]. 


\section{Conclusions}

Despite these limitations, this study provides evidence for the importance of parental catastrophizing cognitions as potential mediators of the relationship between perceived child pain behavior and parental protective responses. Should such findings be replicated in further studies using longitudinal designs, they would strengthen the rationale for targeting reduction of parental catastrophizing in cognitive-behavioral treatments aimed at improving family coping and child functioning for children with chronic gastrointestinal illness.

\section{Conflict of Interests}

The authors declare that there is no conflict of interests regarding the publication of this paper.

\section{Acknowledgments}

This work was supported by NIH Grants R0I HD050345 and 1 UL1 RR025014. These data were presented at the 2013 annual meeting of the American Psychosomatic Society in Miami, FL, by Shelby L. Langer.

\section{References}

[1] M. J. L. Sullivan, B. Thorn, J. A. Haythornthwaite et al., “Theoretical perspectives on the relation between catastrophizing and pain," The Clinical The Journal of Pain, vol. 17, no. 1, pp. 52-64, 2001.

[2] P. J. Quartana, C. M. Campbell, and R. R. Edwards, "Pain catastrophizing a critical review," Expert Review of Neurotherapeutics, vol. 9, no. 5, pp. 745-758, 2009.

[3] J. L. Boothby, B. E. Thorn, L. Y. Overduin, and L. C. Ward, "Catastrophizing and perceived partner responses to pain," Pain, vol. 109, no. 3, pp. 500-506, 2004.

[4] L. F. Buenaver, R. R. Edwards, and J. A. Haythornthwaite, "Painrelated catastrophizing and perceived social responses: interrelationships in the context of chronic pain," Pain, vol. 127, no. 3, pp. 234-242, 2007.

[5] R. R. Edwards, C. M. Campbell, and R. B. Fillingim, "Catastrophizing and experimental pain sensitivity: only in vivo reports of catastrophic cognitions correlate with pain responses," The Journal of Pain, vol. 6, no. 5, pp. 338-339, 2005.

[6] N. D. Giardino, M. P. Jensen, J. A. Turner, D. M. Ehde, and D. D. Cardenas, "Social environment moderates the association between catastrophizing and pain among persons with a spinal cord injury," Pain, vol. 106, no. 1-2, pp. 19-25, 2003.

[7] F. J. Keefe, I. Lipkus, J. C. Lefebvre et al., "The social context of gastrointestinal cancer pain: a preliminary study examining the relation of patient pain catastrophizing to patient perceptions of social support and caregiver stress and negative responses," Pain, vol. 103, no. 1-2, pp. 151-156, 2003.

[8] R. Severeijns, J. W. S. Vlaeyen, M. A. van den Hout, and W. E. J. Weber, "Pain catastrophizing predicts pain intensity, disability, and psychological distress independent of the level of physical impairment," The Clinical The Journal of Pain, vol. 17, no. 2, pp. 165-172, 2001.

[9] M. J. L. Sullivan, W. Stanish, H. Waite, M. Sullivan, and D. A. Tripp, "Catastrophizing, pain, and disability in patients with soft-tissue injuries," Pain, vol. 77, no. 3, pp. 253-260, 1998.
[10] P. Thibault, P. Loisel, M.-J. Durand, R. Catchlove, and M. J. L. Sullivan, "Psychological predictors of pain expression and activity intolerance in chronic pain patients," Pain, vol. 139, no. 1, pp. 47-54, 2008.

[11] G. Crombez, P. Bijttebier, C. Eccleston et al., "The child version of the pain catastrophizing scale (PCS-C): a preliminary validation," Pain, vol. 104, no. 3, pp. 639-646, 2003.

[12] C. Eccleston, G. Crombez, A. Scotford, J. Clinch, and H. Connell, "Adolescent chronic pain: patterns and predictors of emotional distress in adolescents with chronic pain and their parents," Pain, vol. 108, no. 3, pp. 221-229, 2004.

[13] S. L. Langer, J. M. Romano, R. L. Levy, L. S. Walker, and W. E. Whitehead, "Catastrophizing and parental response to child symptom complaints," Children's Health Care, vol. 38, no. 3, pp. 169-184, 2009.

[14] Q. Lu, J. C. I. Tsao, C. D. Myers, S. C. Kim, and L. K. Zeltzer, "Coping predictors of children's laboratory-induced pain tolerance, intensity, and unpleasantness," The Journal of Pain, vol. 8, no. 9, pp. 708-717, 2007.

[15] A. M. Lynch-Jordan, S. Kashikar-Zuck, and K. R. Goldschneider, "Parent perceptions of adolescent pain expression: the adolescent pain behavior questionnaire," Pain, vol. 151, no. 3, pp. 834-842, 2010.

[16] A. M. Lynch-Jordan, S. Kashikar-Zuck, A. Szabova, and K. R. Goldschneider, "The interplay of parent and adolescent catastrophizing and its impact on adolescents'pain, functioning, and pain behavior," The Clinical The Journal of Pain, vol. 29, no. 8, pp. 681-688, 2013.

[17] T. Vervoort, K. D. Craig, L. Goubert et al., "Expressive dimensions of pain catastrophizing: a comparative analysis of school children and children with clinical pain," Pain, vol. 134, no. 1-2, pp. 59-68, 2008.

[18] T. Vervoort, L. Goubert, C. Eccleston, P. Bijttebier, and G. Crombez, "Catastrophic thinking about pain is independently associated with pain severity, disability, and somatic complaints in school children and children with chronic pain," Journal of Pediatric Psychology, vol. 31, no. 7, pp. 674-683, 2006.

[19] T. Vervoort, Z. Trost, and D. M. van Ryckeghem, "Children's selective attention to pain and avoidance behaviour: the role of child and parental catastrophizing about pain," Pain, vol. 154, pp. 1979-1988, 2013.

[20] P. Warschburger, J. Hanig, M. Friedt, C. Posovszky, M. Schier, and C. Calvano, "Health-related quality of life in children with abdominal pain due to functional or organic gastrointestinal disorders," Journal of Pediatric Psychology. In press.

[21] A. K. Rosenstiel and F. J. Keefe, "The use of coping strategies in chronic low back pain patients: relationship to patient characteristics and current adjustment," Pain, vol. 17, no. 1, pp. 33-44, 1983.

[22] M. J. L. Sullivan, S. R. Bishop, and J. Pivik, "The pain catastrophizing scale: development and validation," Psychological Assessment, vol. 7, no. 4, pp. 524-532, 1995.

[23] A. Cano, M. T. Leonard, and A. Franz, "The significant other version of the Pain Catastrophizing Scale (PCS-S): preliminary validation," Pain, vol. 119, no. 1-3, pp. 26-37, 2005.

[24] L. Goubert, C. Eccleston, T. Vervoort, A. Jordan, and G. Crombez, "Parental catastrophizing about their child's pain. The parent version of the Pain Catastrophizing Scale (PCS-P): a preliminary validation," Pain, vol. 123, no. 3, pp. 254-263, 2006.

[25] T. Hechler, T. Vervoort, M. Hamann et al., "Parental catastrophizing about their child's chronic pain: are mothers and fathers 
different?" European The Journal of Pain, vol. 15, no. 5, pp. 515.e1-515.e9, 2011.

[26] L. Caes, T. Vervoort, C. Eccleston, M. Vandenhende, and L. Goubert, "Parental catastrophizing about child's pain and its relationship with activity restriction: the mediating role of parental distress," Pain, vol. 152, no. 1, pp. 212-222, 2011.

[27] L. Caes, T. Vervoort, C. Eccleston, and L. Goubert, "Parents who catastrophize about their child's pain prioritize attempts to control pain," Pain, vol. 153, no. 8, pp. 1695-1701, 2012.

[28] L. Caes, T. Vervoort, P. Devos, J. Verlooy, Y. Benoit, and L. Goubert, "Parental distress and catastrophic thoughts about child pain: implications for parental protective behavior in the context of child leukemia related medical procedures," The Clinical Journal of Pain. In press.

[29] R. S. Lazarus and S. Folkman, Stress, Appraisal, and Coping, Springer, New York, NY, USA, 1984.

[30] L. Caes, T. Vervoort, Z. Trost, and L. Goubert, "Impact of parental catastrophizing and contextual threat on parents' emotional and behavioral responses to their child's pain," Pain, vol. 153, no. 3, pp. 687-695, 2012.

[31] C. Jakobsen, A. Paerregaard, P. Munkholm et al., "Pediatric inflammatory bowel disease: increasing incidence, decreasing surgery rate, and compromised nutritional status: a prospective population-based cohort study 2007-2009," Inflammatory Bowel Diseases, vol. 17, no. 12, pp. 2541-2550, 2011.

[32] M. C. E. Lomer, "Dietary and nutritional considerations for inflammatory bowel disease," Proceedings of the Nutrition Society, vol. 70, no. 3, pp. 329-335, 2011.

[33] G. van Assche, A. Dignass, J. Panes et al., "The second European evidence-based consensus on the diagnosis and management of Crohn's disease: definitions and diagnosis," Journal of Crohn's and Colitis, vol. 4, no. 1, pp. 7-27, 2010.

[34] M. Aloi and S. Cucchiara, "Extradigestive manifestations of IBD in pediatrics," European Review for Medical and Pharmacological Sciences, vol. 13, supplement 1, pp. 23-32, 2009.

[35] L. M. Mackner, K. Vannatta, and W. V. Crandall, "Gender differences in the social functioning of adolescents with inflammatory bowel disease," Journal of Clinical Psychology in Medical Settings, vol. 19, no. 3, pp. 270-276, 2012.

[36] K. A. Hommel, R. N. Greenley, M. H. Maddux, W. N. Gray, and L. M. Mackner, "Self-management in pediatric inflammatory bowel disease: a clinical report of the North American Society for Pediatric GastroenterologyHepatology and Nutrition," Journal of Pediatric Gastroenterology and Nutrition, vol. 57, no. 2, pp. 250-257, 2013.

[37] L. M. MacKner, R. M. Bickmeier, and W. V. Crandall, "Academic achievement, attendance, and school-related quality of life in pediatric inflammatory bowel disease," Journal of Developmental and Behavioral Pediatrics, vol. 33, no. 2, pp. 106-111, 2012.

[38] F. Blondel-Kucharski, C. Chircop, P. Marquis et al., "Healthrelated quality of life in Crohn's disease: a prospective longitudinal study in 231 patients," The American Journal of Gastroenterology, vol. 96, no. 10, pp. 2915-2920, 2001.

[39] L. M. Mackner, R. N. Greenley, E. Szigethy, M. Herzer, K. Deer, and K. A. Hommel, "Psychosocial issues in pediatric inflammatory bowel disease: report of the North American Society for Pediatric Gastroenterology, Hepatology, and Nutrition," Journal of Pediatric Gastroenterology and Nutrition, vol. 56, no. 4, pp. 449-458, 2013.

[40] K. T. Park and D. Bass, "Inflammatory bowel disease-attributable costs and cost-effective strategies in the United States: a review," Inflammatory Bowel Diseases, vol. 17, no. 7, pp. 16031609, 2011.

[41] M. J. L. Sullivan, M. O. Martel, D. A. Tripp, A. Savard, and G. Crombez, "Catastrophic thinking and heightened perception of pain in others," Pain, vol. 123, no. 1-2, pp. 37-44, 2006.

[42] L. Goubert, T. Vervoort, A. Cano, and G. Crombez, "Catastrophizing about their children's pain is related to higher parentchild congruency in pain ratings: an experimental investigation," European The Journal of Pain, vol. 13, no. 2, pp. 196-201, 2009.

[43] M. McCormick, B. Reed-Knight, J. D. Lewis, B. D. Gold, and R. L. Blount, "Coping skills for reducing pain and somatic symptoms in adolescents with IBD," Inflammatory Bowel Diseases, vol. 16, no. 12, pp. 2148-2157, 2010.

[44] B. Reed-Knight, M. McCormick, J. D. Lewis, and R. L. Blount, "Participation and attrition in a coping skills intervention for adolescent girls with inflammatory bowel disease," Journal of Clinical Psychology in Medical Settings, vol. 19, no. 2, pp. 188196, 2012.

[45] D. A. Van Slyke and L. S. Walker, "Mothers' responses to children's pain," The Clinical The Journal of Pain, vol. 22, no. 4, pp. 387-391, 2006.

[46] R. L. Claar, J. W. Guite, K. J. Kaczynski, and D. E. Logan, “Factor structure of the adult responses to children's symptoms: validation in children and adolescents with diverse chronic pain conditions," The Clinical The Journal of Pain, vol. 26, no. 5, pp. 410-417, 2010.

[47] L. S. Walker, R. L. Levy, and W. E. Whitehead, "Validation of a measure of protective parent responses to children's pain," The Clinical The Journal of Pain, vol. 22, no. 8, pp. 712-716, 2006.

[48] R. L. Claar, L. E. Simons, and D. E. Logan, "Parental response to children's pain: the moderating impact of children's emotional distress on symptoms and disability," Pain, vol. 138, no. 1, pp. 172-179, 2008.

[49] R. D. Kerns, J. Haythornthwaite, R. Rosenberg, S. Southwick, E. L. Giller, and M. C. Jacob, "The pain behavior check list (PBCL): factor structure and psychometric properties," Journal of Behavioral Medicine, vol. 14, no. 2, pp. 155-167, 1991.

[50] A. Osman, F. X. Barrios, B. Kopper et al., "The Pain Behavior Check List (PBCL): psychometric properties in a college sample," Journal of Clinical Psychology, vol. 51, no. 6, pp. 775-782, 1995.

[51] D. Ruskin, K. Amaria, F. Warnock, and P. McGrath, "Assessment of pain in infants, children and adolescents," in Handbook of Pain Assessment, D. C. Turk and R. Melzack, Eds., pp. 213-241, Guilford Press, New York, NY, USA, 3rd edition, 2011.

[52] R. L. Claar and L. S. Walker, "Functional assessment of pediatric pain patients: psychometric properties of the functional disability inventory," Pain, vol. 121, no. 1-2, pp. 77-84, 2006.

[53] L. S. Walker and J. W. Greene, "The functional disability inventory: measuring a neglected dimension of child health status," Journal of Pediatric Psychology, vol. 16, no. 1, pp. 39-58, 1991.

[54] L. S. Walker, J. E. Beck, J. Garber, and W. Lambert, "Children's somatization inventory: psychometric properties of the revised form (CSI-24)," Journal of Pediatric Psychology, vol. 34, no. 4, pp. 430-440, 2009.

[55] L. S. Walker, C. A. Smith, J. Garber, and D. A. van Slyke, "Development and validation of the pain response inventory for children," Psychological Assessment, vol. 9, no. 4, pp. 392-405, 1997. 
[56] J. W. Varni, M. Seid, and C. A. Rode, "The PedsQLU゚: measurement model for the pediatric quality of life inventory," Medical Care, vol. 37, no. 2, pp. 126-139, 1999.

[57] C. L. Hicks, C. L. von Baeyer, P. A. Spafford, I. van Korlaar, and B. Goodenough, "The faces pain scale-revised: toward a common metric in pediatric pain measurement," Pain, vol. 93, no. 2, pp. 173-183, 2001.

[58] A. F. Hayes, An Introduction to Mediation, Moderation, and Conditional Process Analysis: A Regression-Based Approach, Guilford Press, New York, NY, USA, 2013.

[59] R. L. Levy, S. L. Langer, L. S. Walker et al., "Cognitive-behavioral therapy for children with functional abdominal pain and their parents decreases pain and other symptoms," The American Journal of Gastroenterology, vol. 105, no. 4, pp. 946-956, 2010.

[60] R. L. Levy, S. L. Langer, L. S. Walker et al., "Twelve-month follow-up of cognitive behavioral therapy for children with functional abdominal pain," JAMA Pediatrics, vol. 167, no. 2, pp. 178-184, 2013.

[61] R. L. Levy, W. E. Whitehead, L. S. Walker et al., "Increased somatic complaints and health-care utilization in children: effects of parent IBS status and parent response to gastrointestinal symptoms," The American Journal of Gastroenterology, vol. 99, no. 12, pp. 2442-2451, 2004.

[62] L. S. Walker, S. E. Williams, C. A. Smith, J. Garber, D. A. van Slyke, and T. A. Lipani, "Parent attention versus distraction: impact on symptom complaints by children with and without chronic functional abdominal pain," Pain, vol. 122, no. 1-2, pp. 43-52, 2006.

[63] C. B. Sieberg, S. Williams, and L. E. Simons, "Do parent protective responses mediate the relation between parent distress and child functional disability among children with chronic pain?" Journal of Pediatric Psychology, vol. 36, no. 9, pp. 1043-1051, 2011.

[64] J. M. Romano, J. A. Turner, L. S. Friedman et al., "Sequential analysis of chronic pain behaviors and spouse responses," Journal of Consulting and Clinical Psychology, vol. 60, no. 5, pp. 777-782, 1992. 


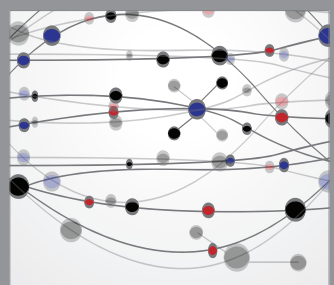

The Scientific World Journal
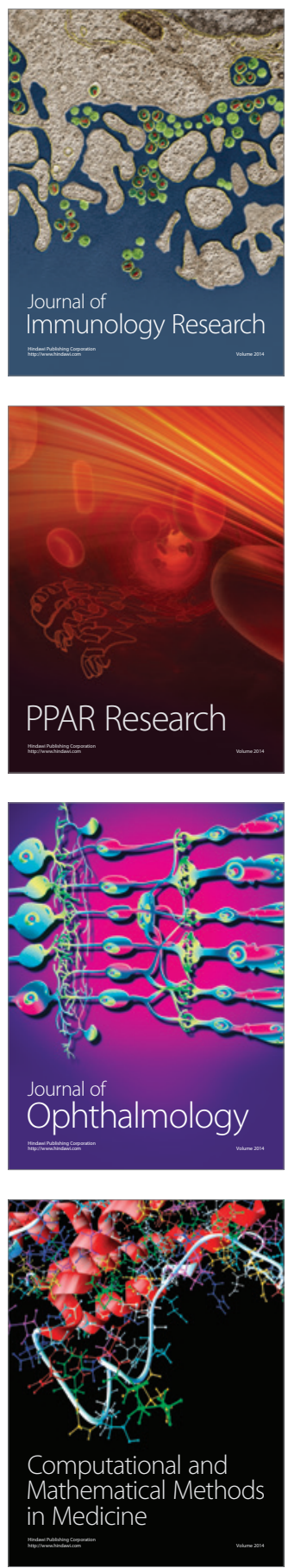

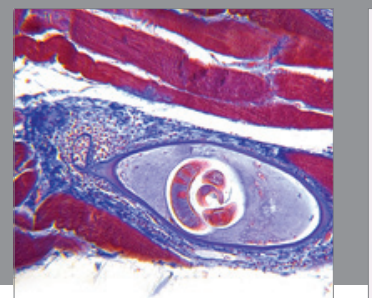

Gastroenterology

Research and Practice
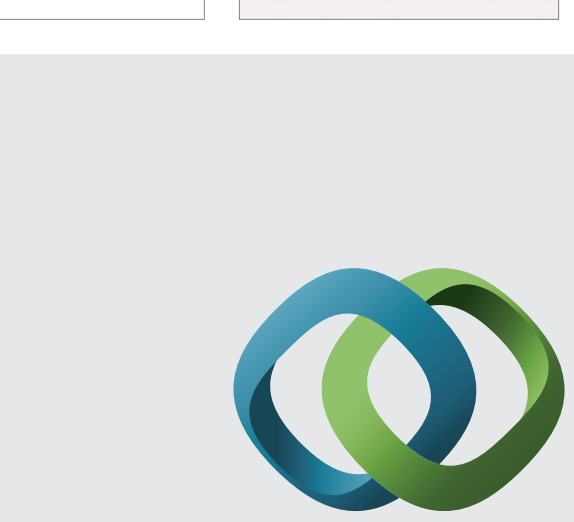

\section{Hindawi}

Submit your manuscripts at

http://www.hindawi.com
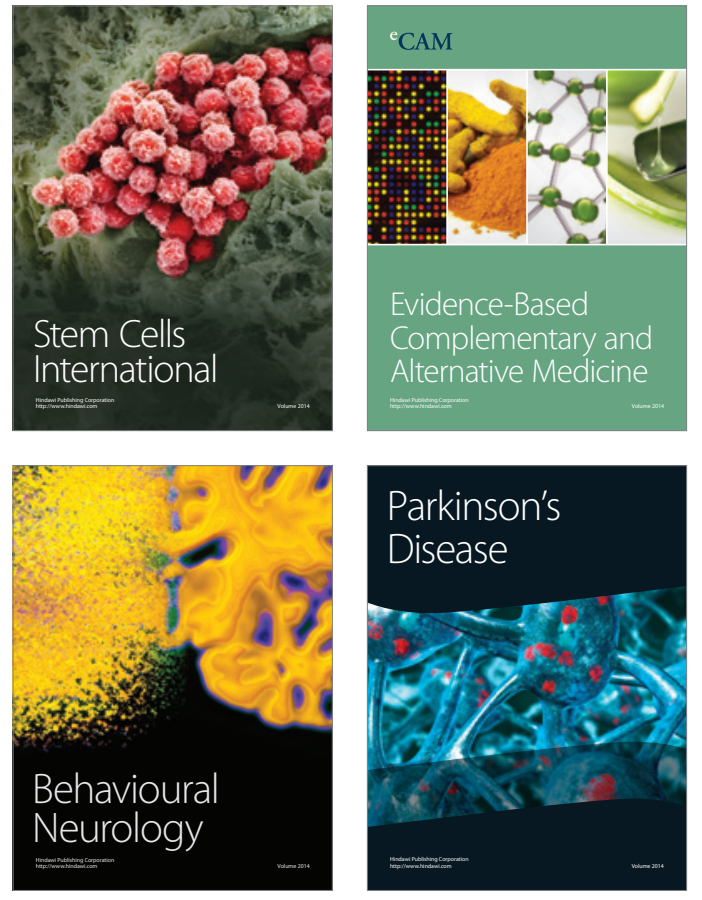
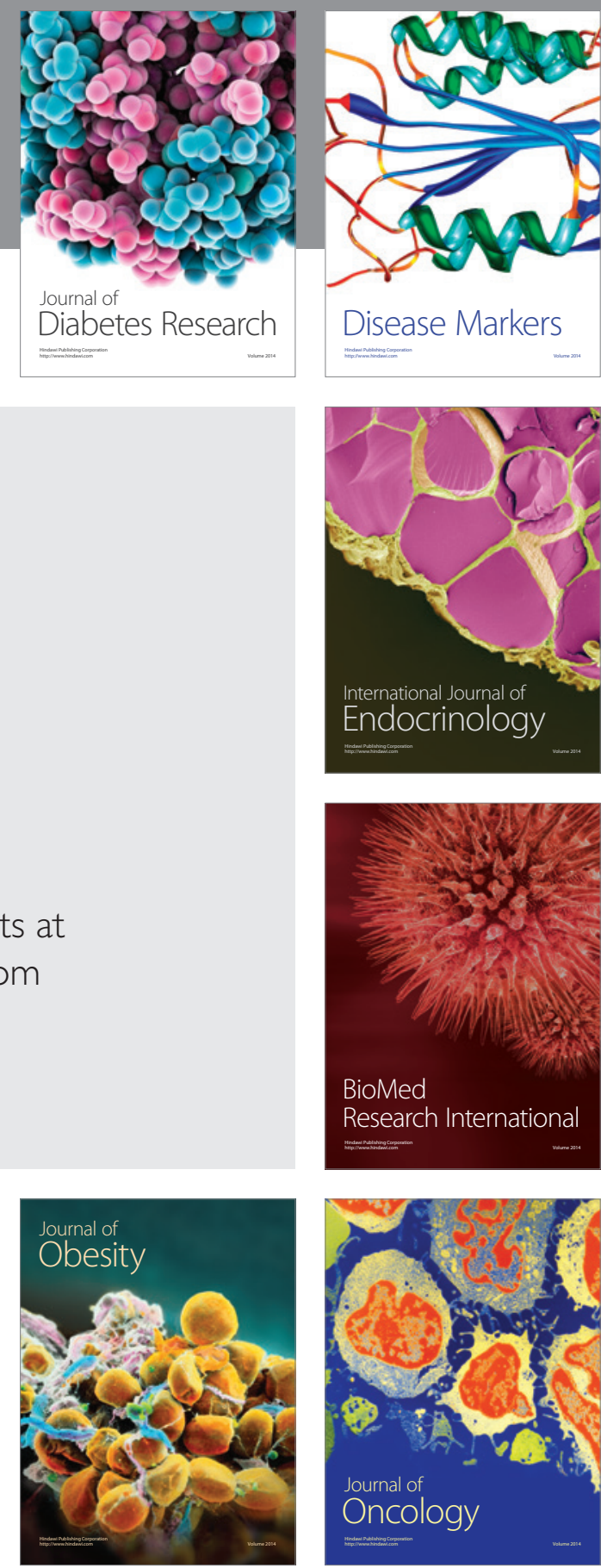

Disease Markers
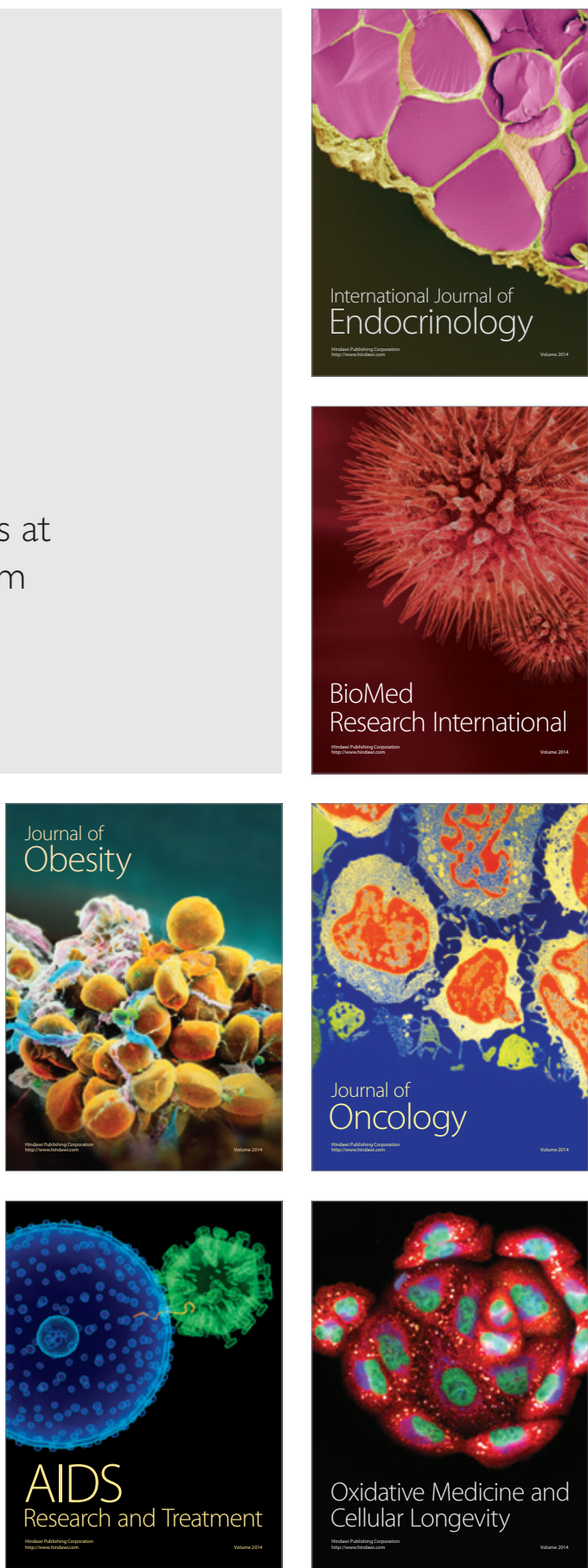